\title{
Comparative evaluation of the antioxidant capacity of ferulic acid and synthesized propionyl ferulate
}

Oluyomi Stephen Adeyemi ${ }^{*}$, Ayonote Divine Ayebakuro', Oluwakemi Josephine Awakan ${ }^{1}$, Olubunmi Atolani², Opeyemi Adejumo $^{2}$, Adewole Ibrahim ${ }^{2}$, Damilare Rotimi ${ }^{1}$, Gaber El-Saber Batiha ${ }^{3}$, John Olusegun Ojediran ${ }^{4}$

${ }^{1}$ Department of Biochemistry, Medicinal Biochemistry, Nanomedicine \& Toxicology Laboratory, Landmark University, PMB 1001, Omu-Aran - 251101, Nigeria. ${ }^{2}$ Department of Chemistry, University of Ilorin, PMB 1515, Ilorin, Nigeria.

${ }^{3}$ Department of Pharmacology and Therapeutics, Faculty of Veterinary Medicine, Damanhour University, Egypt.

${ }^{4}$ Department of Agricultural \& Biosystem Engineering, Landmark University, PMB 1001, Omu-Aran - 251101, Nigeria

\begin{tabular}{|c|c|}
\hline ARTICLE INFO & ABSTRACT \\
\hline $\begin{array}{l}\text { Received on: } 20 / 11 / 2019 \\
\text { Accepted on: } 16 / 01 / 2020 \\
\text { Available online: } 06 / 05 / 2020\end{array}$ & $\begin{array}{l}\text { Ferulic acid (FA) is a polyphenolic compound with demonstrated antioxidant capacity. In this study, propionyl } \\
\text { ferulate (PF) was synthesized and characterized using melting point, ultraviolet spectroscopy, Fourier-transform } \\
\text { infrared spectroscopy, and mass spectrometry. The propionyl ferulate was comparatively evaluated for antioxidant } \\
\text { potential which included the ability to quench reactive species of 2,2-diphenyl-2-picrazyl-hydrazyl (DPPH), hydroxyl, }\end{array}$ \\
\hline $\begin{array}{l}\text { Key words: } \\
\text { Antioxidants, food additives, } \\
\text { medicinal chemistry, } \\
\text { medicinal biochemistry, } \\
\text { natural products. }\end{array}$ & $\begin{array}{l}\text { nitric oxide, and superoxide anion. In addition, the total antioxidant capacity and membrane stabilizing properties of } \\
\text { the ferulate were determined. Comparatively, the spectroscopically characterized PF showed superior scavenging } \\
\text { capacity for the DPPH, hydroxyl, and nitric oxide free radicals when compared to FA. On the contrary, PF showed a } \\
\text { poor scavenging capacity for superoxide anion radicals. Furthermore, PF showed little or no potential for membrane } \\
\text { stability. In conclusion, the data suggest that structurally modifying FA to PF improved the antioxidant capacity for } \\
\text { several free radicals. }\end{array}$ \\
\hline
\end{tabular}

\section{INTRODUCTION}

Antioxidants are chemical or molecular substances that delay or arising from the action of reactive oxygen or nitrogen species (ROS/RNS). They function by electron donation, metal ion chelation, antioxidation, or gene expression regulation. Antioxidants have displayed therapeutic potential in several ailments, such as neurodegenerative diseases, cardiovascular and cancer (Kim et al., 2003; Soobrattee et al., 2005) resulting in rapidly increasing interest in their medicinal application (Wang and Lin, 2000). In addition, the demand for antioxidants in various manufacturing processes, particularly the food industry, has been on the increase, leading to the production of synthetic antioxidants to match this demand. However, in recent years, there has been

\section{${ }^{*}$ Corresponding Author}

Oluyomi Stephen Adeyemi, Department of Biochemistry, The Medicinal Biochemistry, Nanomedicine \& Toxicology Laboratory, Landmark University, PMB 1001, Omu-Aran-251101, Nigeria.

Email:mailto:yomibowa@yahoo.com a shift from synthetic to natural antioxidants (Adeyemi et al., 2018). The preference for the use of natural antioxidants stems from the belief that they have lower toxicity than their synthetic counterparts.

Polyphenolic compounds are naturally occurring antioxidants that are ubiquitous in plant and vegetable diets (Clifford, 1999; Pimentel et al., 2005). This class of natural compounds has also received interest within the past decade as a result of their therapeutic prospects, particularly against cardiovascular-related diseases and cancer (Nardini, 2004). Ferulic acid (4-hydroxy-3-methoxycinnamic acid) (FA), is a natural phenolic and it is one of the most abundant phenols in many plants (D'Archivio et al., 2007; Rechner et al., 2001). FA occurs freely, or in dimers, or as esters bound to polysaccharides or proteins in cell walls, such as arabinoxylan in grass and xyloglucan in bamboo (Fazary and Ju, 2007; Rumbold et al., 2003). FA consists of a hydroxyl, carboxyl, and methoxy group, an ethylenic bond, and a benzene ring (Zhang et al., 2003). The chemical features of FA have been exploited in the synthesis of diverse derivatives such as esters, ethers, amides, anhydrides, acyl chlorides, acid polymers, 
nitrobenzenes, benzene sulfonic acids, and benzene halides of FA (Zhang et al., 2003). The scavenging properties of FA may be attributed in presence of electron-donating groups; 3-methoxy and 4-hydroxyl (Kanasaki et al., 2002). One of these characteristics is the presence of the electron-donating groups on the ring structure (3-methoxy and 4-hydroxyl). The second is the presence of a carboxylic acid group adjacent to an unsaturated carboncarbon double bond (Kanasaki et al., 2002). The carboxylic acid group also provides support, through which it binds to membrane bilayers, thereby preventing lipid peroxidation (Kanasaki et al., 2002). Furthermore, FA has the capacity to negate radical chain reactions through polymerization and is known to increase crosslinkages in polysaccharides and other polymers, giving it capacity to prevent UV-radiation damage (dos Santos et al., 2008).

Although FA has been shown to have a low toxicity index relative to its various biological and medicinal activities, its clinical use is still underexplored. Its use is greatly limited by the fact that it is unstable in different solvents and has a low interaction with lipids (Compton et al., 2012; Qin et al., 2013; Stamatis et al., 2001). Therefore, the focus has shifted to the use of FA derivatives as possible alternatives to FA due to their lipophilic properties. In this study, we synthesized propionyl ferulate (PF) and evaluated the antioxidant potential of the derivative compared with FA.

\section{MATERIALS AND METHODS}

\section{Experimental}

Analytical grade reagents used included FA and L-ascorbic acid (Sigma-Aldrich, St. Louis, MO). The monitoring of reaction and purity check were accomplished by thin-layer chromatography (TLC) on precoated silica gel $\left(0.25 \mathrm{~mm} 60 \mathrm{~F}_{254}\right.$ plates, Merck, Germany) and observed in UV light (254 and 365 $\mathrm{nm})$. A stock solution $(2 \mathrm{mg} / \mathrm{ml})$ of PF or FA was prepared in methanol.

\section{Synthesis of PF}

First, the reaction was initiated by dissolving $0.97 \mathrm{~g}$ of FA $(5 \mathrm{mmol}, 194 \mathrm{~g})$ in $5 \% \mathrm{NaOH}(\mathrm{aq})$. After 30 min of continuous stirring on ice $\left(10^{\circ} \mathrm{C}\right)$ the resulting solid was collected via filtration and washed with cold saturated brine solution to purify (Scheme 1). The product obtained was dried at room temperature.

\section{Propionyl ferulate}

It is a white powder, having m.p. $162-164^{\circ} \mathrm{C}$, yield $37 \%$, ( $\mathrm{R}_{\mathrm{f}}$ is 0.60 in dichloromethane), ( $\lambda_{\max }$ is $321 \mathrm{~nm}$ with $\left.2.5 \mathrm{abs}\right)$, IR using the $\mathrm{KBr}$ pellet method; $\mathrm{V}_{\max }, \mathrm{cm}^{-1}-3437,2939,2366,1687$, $1625,1425,1126 ; \mathrm{C}_{13} \mathrm{H}_{14} \mathrm{O}_{5} ; \mathrm{MW}=250.25$; MS: $m / z(\%): 150,135$, $118,107$.

The melting point was obtained by using a melting point apparatus (Electrothermal, UK), whereas absorption data were recorded by using a UV-VIS spectrophotometer (Beckman Coulter DU 730 Life Sciences, UK). The infrared spectrum was obtained by the $\mathrm{KBr}$ pellet protocol on a Shimadzu (8400S) Fourier-transform infrared spectrometer. The molecular weight was estimated by mass spectrometry in ionization mode at $70 \mathrm{eV}$ (MS-QP 2010 PLUS, Shimadzu, Japan), with Finnigan MAT ion trap detector.

\section{In vitro antioxidant screening}

Assay for 2,2-diphenyl-2-picryl-hydrazyl (DPPH) scavenging potential

The DPPH radical scavenging assay was performed in line with the method described by Devi et al. (2011). An aliquot $(0.1 \mathrm{ml})$ of PF, FA, or L-ascorbic acid (concentration range: 0.01 , 0.05 , and $0.1 \mu \mathrm{g} / \mathrm{ml}$, respectively) was added to $2.9 \mathrm{ml}$ of $0.1 \mathrm{mM}$ DPPH-methanol. After 30 min of vigorous shaking and incubation in the dark, the absorbance of mixture was read at $517 \mathrm{~nm}$ on a spectrophotometer (Jenway, Staffordshire, UK). The control contained $0.1 \mathrm{ml}$ of methanol and $2.9 \mathrm{ml}$ of DPPH, whereas methanol only was used as blank. The \% activity was estimated using the following expression:

$\%$ Activity $=\left[1\left(\frac{\text { Absorbance of sample }- \text { Absorbance of blank }}{\text { Absorbance of control }}\right)\right] \times 100$

\section{Assay for nitric oxide radical scavenging potential}

The nitric oxide radical scavenging assay was carried out as described by Ilavarasan et al.. (2005). An aliquot $(0.5 \mathrm{ml})$ of PF, FA, or L-ascorbic acid (concentration range: 0.01, 0.05, and $0.1 \mu \mathrm{g} / \mathrm{ml}$, respectively) was added to $0.5 \mathrm{ml}$ of sodium nitroprusside. This mixture was incubated for 5 hours at $25^{\circ} \mathrm{C}$. Thereafter, $0.5 \mathrm{~mL}$ of the incubated mixture was added to $0.5 \mathrm{~mL}$ of Greiss reagent, and the absorbance was read at $540 \mathrm{~nm}$ on UV/ VIS spectrophotometer. The blank contained $0.5 \mathrm{ml}$ of distilled water, $0.5 \mathrm{ml}$ of sodium nitroprusside, and $0.5 \mathrm{ml}$ of Griess reagent and had an absorbance of $540 \mathrm{~nm}$. The following expression was used to estimate the \% activity:

$\%$ Activity $=\frac{\{(\text { Abs control }- \text { Abs sample })\}}{(\text { Abs control })} \times 100$

\section{Assay for superoxide anion scavenging potential}

This assay was carried out using as described elsewhere (Luo et al., 2002). Briefly, $1 \mathrm{~mL}$ of PF, FA, or L-ascorbic acid (concentration range: $0.01,0.05$, and $0.1 \mu \mathrm{g} / \mathrm{mL}$ ) was added to $4.5 \mathrm{~mL}$ of Tris- $\mathrm{HCl}$ buffer. After $20 \mathrm{~min}$ incubation at $25^{\circ} \mathrm{C}, 0.4$ $\mathrm{mL}$ of pyrogallol was added and reaction allowed for $4 \mathrm{~min}$. This was followed by termination of reaction with $0.1 \mathrm{~mL}$ of $\mathrm{HCl}$. The mixture was pelleted at $1,000 \mathrm{~g}$ for 15 minutes (model C5, LW Scientific, GA), and the absorbance at $325 \mathrm{~nm}$ was recorded on UV/VIS spectrophotometer.

The blank contained $1 \mathrm{ml}$ of distilled water, $4.5 \mathrm{ml}$ of Tris- $\mathrm{HCl}$ buffer, $0.4 \mathrm{ml}$ of pyrogallol, and $0.1 \mathrm{ml}$ of $\mathrm{HCl}$. The \% activity was estimated using the following expression:

$\%$ Activity $=\frac{\{(\text { Abs control }- \text { Abs sample })\}}{(\text { Abs control })} \times 100$

Assay for total antioxidant capacity

The assay was performed as described previously (Saha et al., 2019). Briefly, $0.3 \mathrm{ml}$ of PF, FA, or L-ascorbic acid 
(concentration range: $0.01,0.05$, and $0.1 \mu \mathrm{g} / \mathrm{ml}$, respectively) was added to $3 \mathrm{ml}$ of reagent solution $(0.6 \mathrm{M}$ sulfuric acid, 28 $\mathrm{mM}$ sodium phosphate, and $4 \mathrm{mM}$ ammonium molybdate). This mixture was incubated at $95^{\circ} \mathrm{C}$ for 90 minutes. This was followed by cooling mixture at room temperature and recording the absorbance at $695 \mathrm{~nm}$ on a spectrophotometer against a blank. For control, methanol was used instead of the PF or FA and the activity was expressed as gram equivalents of L-ascorbic acid.

\section{Assay for membrane stabilizing effect}

This assay was done following a method described by Malomo et al. (2011). The assay mixture consisted of $2 \mathrm{ml}$ of hyposaline, $1 \mathrm{ml}$ of phosphate buffer, erythrocyte suspension in $1.5 \mathrm{ml}$ of isosaline, and $1 \mathrm{ml}$ of PF, FA, or reference compound (concentration range: $0.01,0.05$ and $0.1 \mu \mathrm{g} / \mathrm{ml}$, respectively). The control lacked the drug or test samples, whereas the drug control and test samples lacked the erythrocyte suspension. Isosaline was added to the controls to make the reaction volumes up to $4.5 \mathrm{ml}$. After $30 \mathrm{~min}$ of incubation at $56^{\circ} \mathrm{C}$, the mixture was cooled and pelleted at $1000 \mathrm{~g}$ for $15 \mathrm{~min}$.

The absorbance of the supernatant was read at $560 \mathrm{~nm}$ on UV/VIS spectrophotometer. The \% membrane stabilizing activity was estimated as follows:

$\%$ Activity $=\left(\frac{\text { Drug or Sample test value }- \text { Drug or Sample Test control }}{\text { Control Value }}\right) \times 100$

\section{Statistical analysis}

Results were analyzed by a one-way ANOVA (GraphPad Prism 5, CA, USA) and are presented as the mean of replicates \pm standard error of mean (SEM). The Tukey's post-Hoc was used for multiple comparisons and level of significance was taken at $p<.05$.

\section{RESULTS}

\section{Synthesis and characterization of PF}

The synthesis of PF was accomplished by treating FA dissolved in sodium hydroxide with propionic anhydride. The intermediate sodium salt of FA facilitated the reaction with propionic anhydride. The reaction was monitored by TLC and reached completion in 30 minutes.

The infrared spectrum of the product obtained $(\mathrm{PF})$, a white powder with a melting point of $162^{\circ} \mathrm{C}-164^{\circ} \mathrm{C}$, showed strong absorption bands at 3,437 and $1,687 \mathrm{~cm}^{-1}$ corresponding to $\mathrm{OH}$ and CO stretching vibrations, respectively Supplementary data.

\section{In vitro antioxidant assays}

The comparative evaluation for the in vitro antioxidant potential showed that PF had better scavenging properties against DPPH, hydroxyl, and nitric oxide radicals compared with FA (Figs. 1-3). At all concentrations, PF showed superior scavenging activity against DPPH compared with FA or L-ascorbic acid. Similarly, PF at 0.01 and $0.05 \mu \mathrm{g} / \mathrm{ml}$ exhibited better scavenging activity against the hydroxyl radical compared with FA or L-ascorbic acid. In addition, PF showed a strong nitric oxide radical scavenging activity compared with FA or L-ascorbic

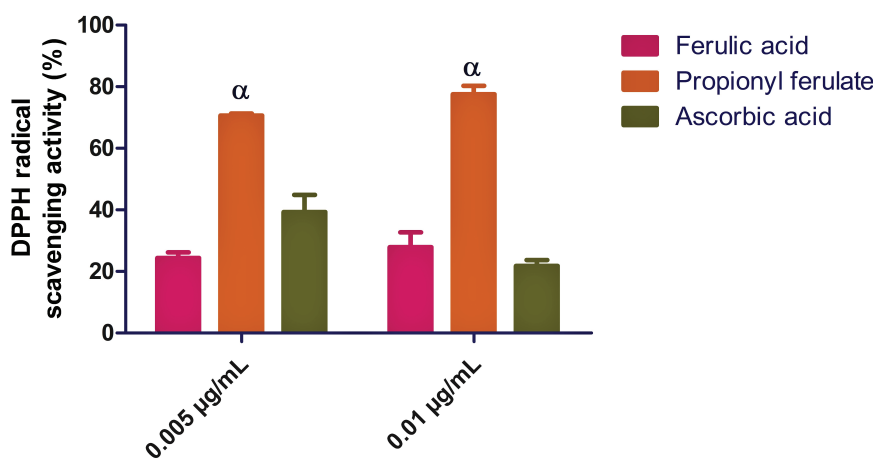

Figure 1. DPPH radical scavenging activity of propionyl ferulate, ferulic acid, and L-ascorbic acid (standard). Data are expressed as the mean of three replicates \pm SEM. $\alpha$ is significant at $p<0.05$ versus ferulic acid and/or L-ascorbic acid.

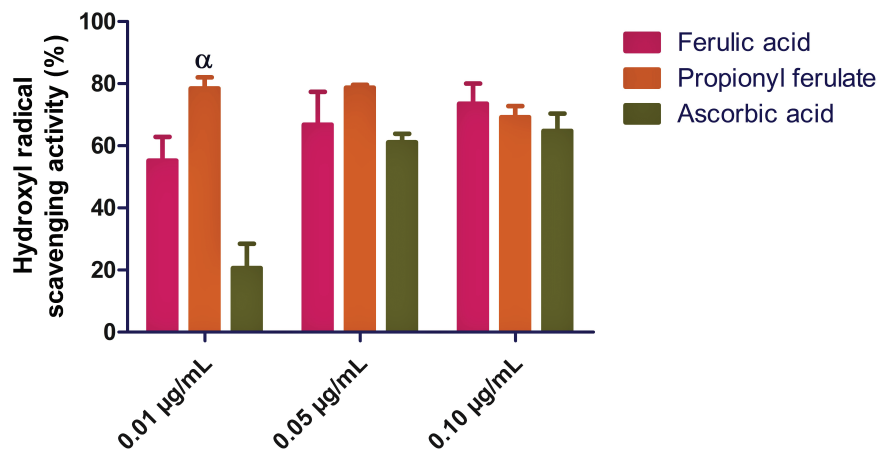

Figure 2. Hydroxyl radical scavenging activity of propionyl ferulate, ferulic acid, and L-ascorbic acid (standard). Data are expressed as the mean of three replicates \pm SEM. $\alpha$ is significant at $p<0.05$ versus ferulic acid and/or L-ascorbic acid.

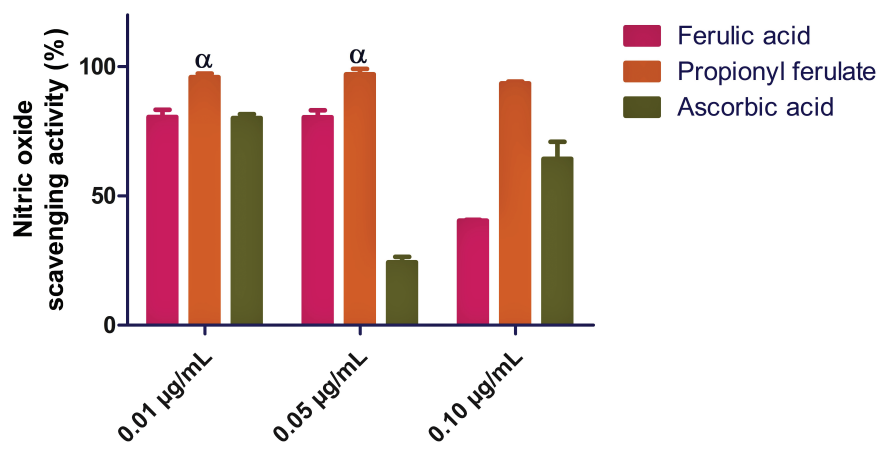

Figure 3. Nitric oxide radical scavenging activity of propionyl ferulate, ferulic acid, and L-ascorbic acid (standard). Data are expressed as the mean of three replicates \pm SEM. $\alpha$ is significant at $p<0.05$ versus ferulic acid and/or L-ascorbic acid.

acid. On the contrary, FA showed a greater scavenging activity against the superoxide anion (Fig. 4). FA also had a higher total antioxidant and membrane-stabilizing capacity than $\mathrm{PF}$ (Figs. 5 and 6). Meanwhile, acetylsalicylic acid which was positive drug control for the membrane stability assay showed better membrane stability than either FA or PF. Indeed, PF showed the least membrane-stabilizing capacity across all concentrations. 


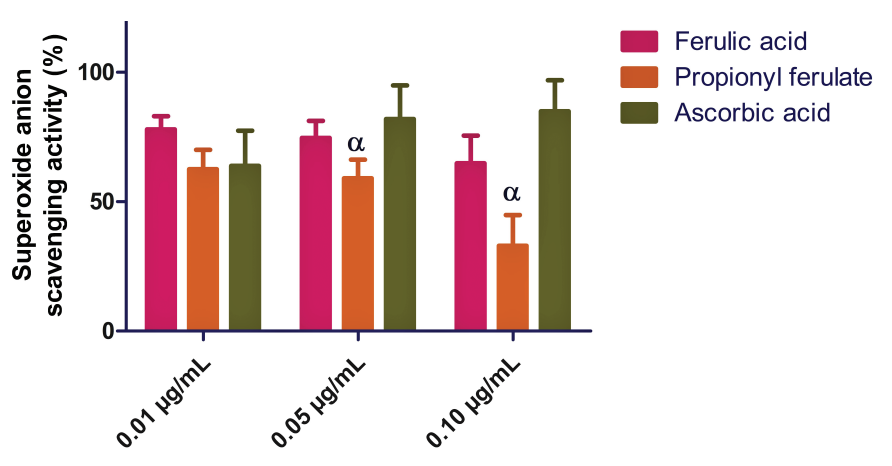

Figure 4. Superoxide anion scavenging activity of propionyl ferulate, ferulic acid, and L-ascorbic acid (standard). Data are expressed as the mean of three replicates \pm SEM. $\alpha$ is significant at $p<0.05$ versus ferulic acid and/or L-ascorbic acid.

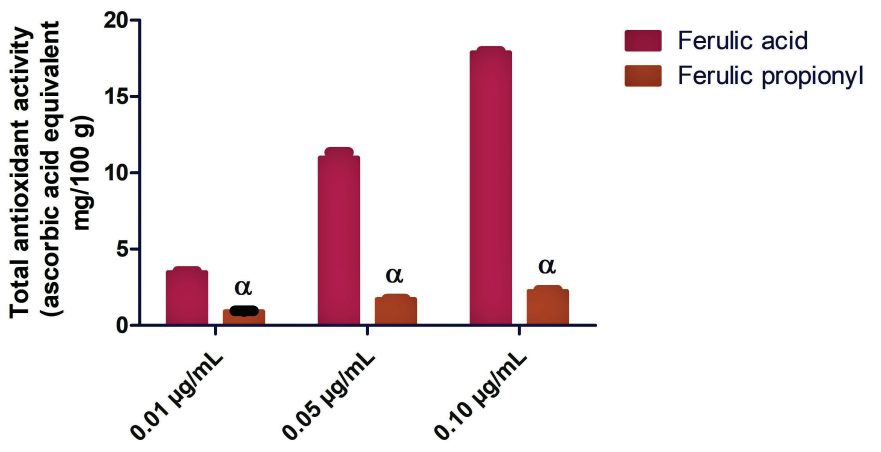

Figure 5. Total antioxidant capacity of propionyl ferulate and ferulic acid expressed as a number of gram equivalents of L-ascorbic acid. Data are expressed as the mean of three replicates \pm SEM. $\alpha$ is significant at $p<0.05$ versus ferulic acid.

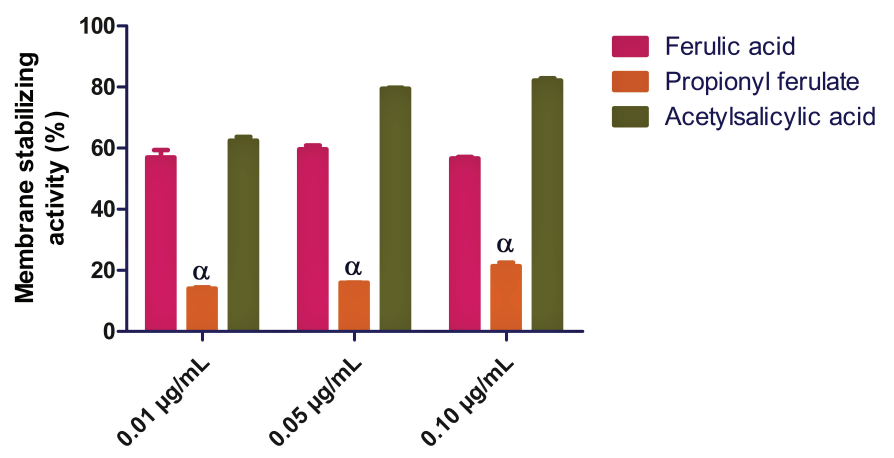

Figure 6. Percentage membrane stabilizing activity of ferulic acid, propionyl ferulate, and acetylsalicylic acid (standard). Data are expressed as the mean of three replicates \pm SEM. $\alpha$ is significant at $p<0.05$ versus ferulic acid and/or acetylsalicylic acid.

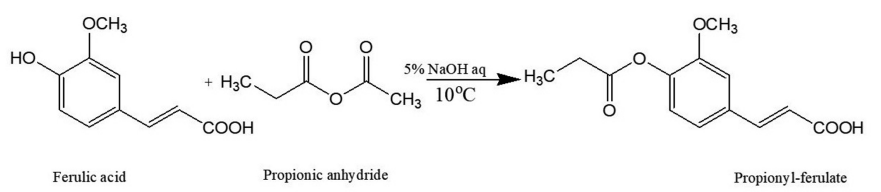

Scheme 1. Synthesis of PF.

\section{DISCUSSION}

Various methods have been used to synthesize the esters of phenolics to improve their bioactivity (Hosoda et al., 2002; Zhao et al., 2015). The strong hydrophobicity of FA, a hydroxycinnamic acid, has necessitated the synthesis of derivatives with improved bioactivity and reduced toxicity (Anselmi et al., 2005; Nyaradzo et al., 2009; Rakotondramanana et al., 2007). The synthesis of the PF was accomplished following a standard procedure (Adeyemi et al., 2019). The PF synthesized and characterized in this study had UV, IR, and MS data that conform to the indicated structure.

To maximize the antioxidant and/or medicinal value of FA and to circumvent its physicochemical and biological disadvantages, researchers previously synthesized several derivatives (Adeyemi et al., 2018; 2019). In this study, we synthesized PF and comparatively evaluated it for antioxidant potential. The data indicate that PF showed a superior antioxidant capacity to either FA or ascorbic acid. It also had a superior scavenging activity for the DPPH radical compared to FA or ascorbic acid. This finding differs from the previous study (Karamac et al., 2005) which showed that FA had a better antioxidant capacity than its derivatives. In addition, PF showed better scavenging capacity for hydroxyl and nitrogen radicals when compared with FA or ascorbic acid. These findings combine to indicate that structurally modifying FA to form PF did not compromise its antioxidant potential. This is consistent with the previous findings (Adeyemi et al., 2018), in which FA derivatives showed superior antioxidant activity compared with FA.

The superior total antioxidant and membrane-stabilizing capacity observed with FA over PF might be attributable to the polarity of the assay method; thus, since PF is less polar, its functional properties may be inaccessible in the assay. Further experiments are needed to confirm this speculation. PF's poor capacity for membrane stabilization could also be due to its lower hydrophobicity than FA. In this scenario, the reduced hydrophobicity of PF might decrease its interaction with the membrane in the lipid phase, thereby limiting its capacity to offer protection in this phase. This line of thought is further reinforced by the finding that FA showed considerable membrane protection. Meanwhile, FA had better total antioxidant capacity as well as higher scavenging activity for superoxide anion radicals compared with PF. This may not be unexpected since FA possesses strong antioxidant potential (Kanski et al., 2002).

FA, which is a monohydrated cinnamic acid, can form derivatives with distinct structural orientations. Thus, evaluating its derivatives is essential to discover the changes in biological activity (Calheiros et al., 2009). Of the various approaches for synthesizing compounds from FA, esterification is increasingly popular among scientists because the resulting compounds tend to have the higher antioxidant ability and increased lipophilic properties than FA itself (Adeyemi et al., 2018). The alkyl ferulates are esterified ferulates that have been reported to have higher antioxidant activity in a membranous system (Anselmi et al., 2005), to prevent neurodegenerative disorders (Anselmi et al., 2004), to possess anticancer potential (Sultana, 2012), and to possess the ability to penetrate the skin using intercellular pathways (Murakami et al., 2000). Alkyl ferulates include ferulic propyl, which could be single-bonded (-anyl), double-bonded (-enyl), or 
triple-bonded (-ynyl). In this study, the focus was on the single-bond derivative, PF. The study showed that this structural modification of FA did not inhibit the antioxidant property of PF compared with FA but, rather, enhanced it. This supports the idea that the degree of freedom introduced by the FA modification, especially by esterification, may be indicative of rotation around the $(\mathrm{C}-\mathrm{O})$ bond, which could be a destabilizing factor that could increase their scavenging property (Calheiros et al., 2009; Zhang et al., 2010).

\section{CONCLUSION}

Findings revealed that PF had higher antioxidant activities than FA. The data indicate that structurally modifying FA can significantly improve its antioxidant activity. Additional investigations are warranted to explore the bioactive prospects of PF.

\section{ACKNOWLEDGMENTS}

The authors would like to thank the laboratory staff in Biochemistry at Landmark University for their technical support. Also, Ed and Rhoda Perozzi and Bruce Barron are appreciated for editorial assistance.

\section{CONFLICTS OF INTEREST}

The authors declare that they have no conflicts of interest.

\section{AUTHOR CONTRIBUTIONS}

OSA - concept, analysis, drafting, and final review; ADA - data collection, analysis, and final review; OJA - data collection, analysis, final review; OA — concept, analysis, drafting, final review; OA-data collection analysis and final review; AI - data collection, analysis, and final review; DR - data collection, analysis, and final review; TCE-data collection, analysis, and final review; GEB - data collection, analysis, and final review; JOO — data collection, analysis, and final review; OOO — data collection, analysis, and final review.

\section{REFERENCES}

Adeyemi O, Atolani O, Banerjee P, Arolasafe G, Preissner R, Etukudoh P, Ibraheem O. Computational and experimental validation of antioxidant properties of synthesized bioactive ferulic acid derivatives. Int $\mathrm{J}$ Food Prop, 2018; 21(1):86-98.

Adeyemi OS, Awakan OJ, Atolani O, Iyeye CO, Oweibo OO, Adejumo OJ, Adewole I, Batiha GE. New Ferulic Acid Derivatives Protect Against Carbon Tetrachloride-Induced Liver Injury in Rats. The Open Biochem J, 2019; 13:13-22.

Anselmi C, Bernardi F, Centini M, Gaggelli E, Gaggelli N, Valensin D, Valensin G. Interaction of ferulic acidderivatives with human erythrocytes monitored by pulse fieldgradient NMR diffusion and NMR relaxation studies. Chem Phys Lipids, 2005; 134(2):109-17.

Anselmi C, Centini M, Andreassi M, Buonocore A, Rosa C, Facino R, Sega A, Tsuno F. Conformational analysis: a tool for the elucidation of the antioxidant properties of ferulic acid derivatives in membrane models. J Pharm Biomed Anal, 2004; 35(5):1241-9.

Calheiros R, Borges F, Marques M. Conformational behaviour of biologically active ferulic acid derivatives. J Mol Struct: Theochem, 2009; 913(1-3):146-56.

Clifford M. Chlorogenic acids and other cinnamates-nature, occurrence and dietary burden. J Sci Food Agric, 1999; 79(3):362-72.

Compton D, Laszlo J, Evans K. Antioxidant properties of feruloyl glycerol derivatives. Ind Crops Prod, 2012; 36(1):217-21.
D'Archivio M, Filesi C, Benedetto R, Gargiulo R, Giovannini C, Masella R. Polyphenols, dietary sources and bioavailability. Ann Ist Super Sanità, 2007; 43(4):348-61.

Devi G, Manivannan K, Thirumaran G, Rajathi F, Anantharaman P. In vitro antioxidant activities of selected seaweeds from Southeast coast of India. Asian Pac J Trop Med, 2011; 4(3):205-11.

dos Santos W, Ferrarese M, Nakamura C, Mourão K, Mangolin C, Ferrarese-Filho O. Soybean (glycine max) root lignification induced by ferulic acid. the possible mode of action. J Chem Eco, 2008; 34(9):1230-41.

Fazary A, Ju Y. Feruloylesterases as biotechnological tools: current and future perspectives. Acta Biochim Biophy Sinica, 2007; 39(11):811-28

Hosoda A, Ozaki Y, Kashiwada A, Mutoh M, Wakabayashi K, Mizuno K, Nomura E, Taniguchi H. Syntheses of ferulic acid derivatives and their suppressive effects on cyclooxygenase-2promoter activity. Bioorg Med Chem, 2002; 10(4):1189-96.

Ilavarasan R, Mallika M, Venkataraman S. Antiinflammatory and antioxidant activities of Cassia fistula linn. bark extracts. Afr J Trad Comp Alter Med, 2005; 2(1):70-85.

Kanasaki H, Yonehara T, Yamamoto H, Takeuchi Y, Fukunaga K, Takahashi K, Miyazaki K, Miyamoto E. Differential regulation of pituitary hormone secretion and gene expression by thyrotropin-releasing hormone. A role for mitogen-activated protein kinase signaling cascade in rat pituitary GH3 cells. Biol Reprod, 2002; 67(1):107-13.

Kanski J, Aksenova M, Stoyanova A, Butterfield D. Ferulic acid antioxidant protection against hydroxyl and peroxyl radical oxidation in synaptosomal and neuronal cell culture systems in vitro: structure-activity studies. J Nutri Biochem, 2002; 13(5):273-81.

Karamac M., Kosinka A, Pegg RB. Comparison of radicalscavenging activities for selected phenolic acids. Pol J Food Nutri Sci, $2005 ; 14: 165-70$

Kim H, Jeong T, Lee M, Park Y, Choi M. Lipid-lowering efficacy of hesperetin metabolites in high-cholesterol fed rats. Clin Chim Acta, 2003; 327(1-2):129-37.

Luo X, Basile M, Kennelly E. Polyphenolic antioxidants from the fruits of Chrysophyllum cainito L. (Star Apple). J Agric Food Chem, 2002; 50(6):1379-82.

Malomo S, Ore A, Yakubu M. In vitro and in vivo antioxidant activities of the aqueous extract of Celosia argentea leaves. Indian J Pharmacol, 2011; 43(3):278.

Murakami A, Kadota M, Takahashi D, Taniguchi H, Nomura E, Hosoda A, Tsuno T, Maruta Y, Ohigashi H, Koshimizu K. Suppressive effects of novel ferulic acid derivatives on cellular responses induced by phorbol ester, and by combined lipopolysaccharide and interferon- $\gamma$. Cancer Lett, 2000; 157(1):77-85.

Nardini M. Determination of free and bound phenolic acids in beer. Food Chem, 2004; 84(1):137-43.

Nyaradzo T, Murefu C, Riva S, Burton SG. Lipase-catalysed synthesis of esters of ferulicacid with natural compounds and evaluation of their antioxidant properties. J Mol Catal B-Enzym, 2009; 56(4):277-82.

Pimentel C, Francki V, Gollucke A.Alimentos Funcionais. Introdução Às Principais Substâncias Bioativas Em Alimentos. Varela, Sao Paulo, Brazil, p 100, 2005.

Qin F, Dou H, Bi Y, Lin T, Sun S, Yang G, Liu W. Progress on synthesis of water soluble glycerylferulates. J Henan Univ Tech (Nat. Sci. Edn), 2013; 34:101-5.

Rakotondramanana D, Delomenède $\mathrm{M}$, Baltas $\mathrm{M}$, Duran $\mathrm{H}$, Bedos-Belval F, Rasoanaivo P, Negre-Salvayre A, Gornitzka H. Synthesis of ferulic ester dimers, functionalisation and biological evaluation as potential antiatherogenic and antiplasmodial agents. Bioorg Med Chem 2007; 15(18):6018-26.

Rechner A, Pannala A, Rice-Evans C. Caffeic acid derivatives in artichoke extract are metabolised to phenolic acidsin vivo. Free Rad Res, 2001; 35(2):195-202. 
Rumbold K, Biely P, Mastihubova M, Gudel J, Gubitz G, Robra $\mathrm{K}$, Prior B. Purification and properties of a feruloyl esterase involved in lignocellulose degradation by Aureobasidium pullulans. Appl Environ Microbiol, 2003; 69(9):5622-6.

Saha M, Hasan S, Akter R, Hossain M, Alam M, Alam S, Mazumder M. In Vitro free radical scavenging activity of methanol extract of the leaves of Mimusops elengi Linn. Bangl J Vet Med, 2019; 6:197-202.

Soobrattee M, Neergheen V, Luximon-Ramma A, Aruoma $\mathrm{O}$, Bahorun T. Phenolics as potential antioxidant therapeutic agents: mechanism and actions. Mut Res-Fund Mol M, 2005; 579(1-2):200-13.

Stamatis H, Sereti V, Kolisis F. Enzymatic synthesis of hydrophilic and hydrophobic derivatives of natural phenolic acids in organic media. J Mol Cataly B- Enzym, 2001; 11(4-6):323-8.

Sultana R. Ferulic acid ethyl ester as a potential therapy in neurodegenerative disorders. Biochim Biophy Acta, 2012; 1822(5):748-52.

Wang S, Lin H. Antioxidant activity in fruits and leaves of blackberry, raspberry, and strawberry varies with cultivar and developmental stage. J Agric Food Chem, 2000; 48(2):140-6.

Zhang L, Al-Suwayeh S, Hsieh P, Fang J. A comparison of skin delivery of ferulic acid and its derivatives: Evaluation of their efficacy and safety. Int J Pharma, 2010; 399(1-2):44-51.
Zhang Y, Wei C, Wang J. Study on the synthesis and molecular modification of ferulic acid. J Huaiyin Teachers Coll, 2003; 2:50-3.

Zhao D, Ma L, Lu K, He J. Solid phase syntheses of ferulic acid derivatives acetyl feruloyl tyrosine and acetyl feruloylvalyl tyrosine. Open Biotechnol J, 2015; 9:1-5.

\section{How to cite this article:}

Adeyemi OS, Ayebakuro AD, Awakan OJ, Atolani O, Adejumo O, Ibrahim A, Rotimi D, Batiha GE, Ojediran JO. Comparative evaluation of the antioxidant capacity of ferulic acid and synthesized propionyl ferulate. J Appl Pharm Sci, 2020; 10(05):097-103. 


\section{SUPPLEMENTARY DATA}

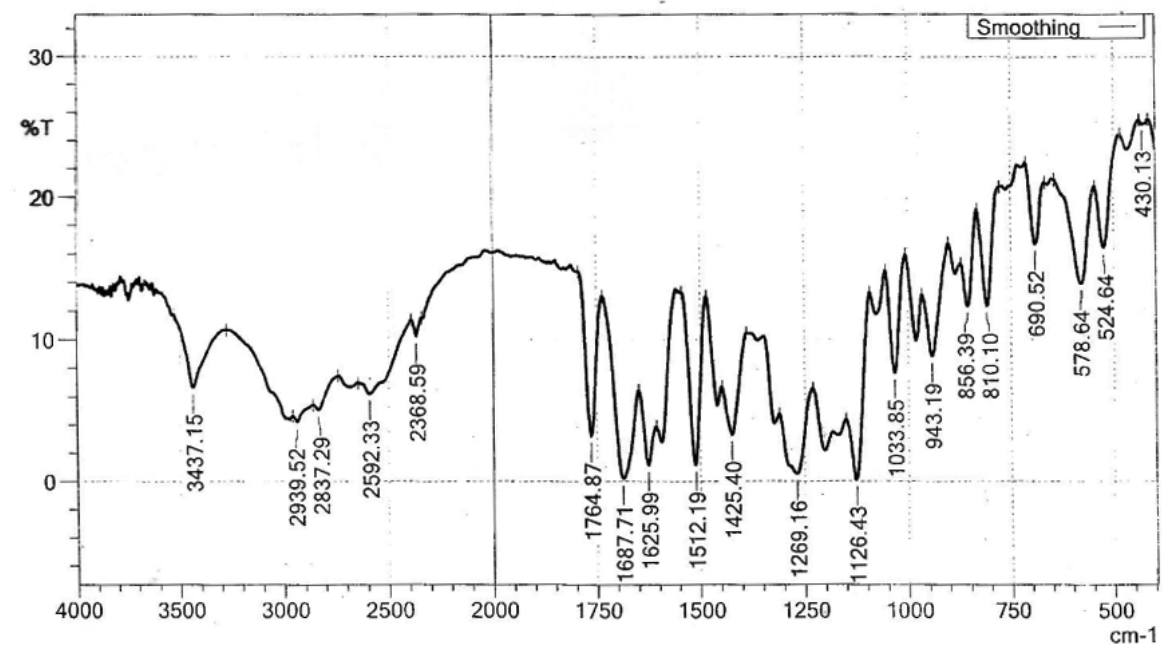

FT-IR Spectrum of Product

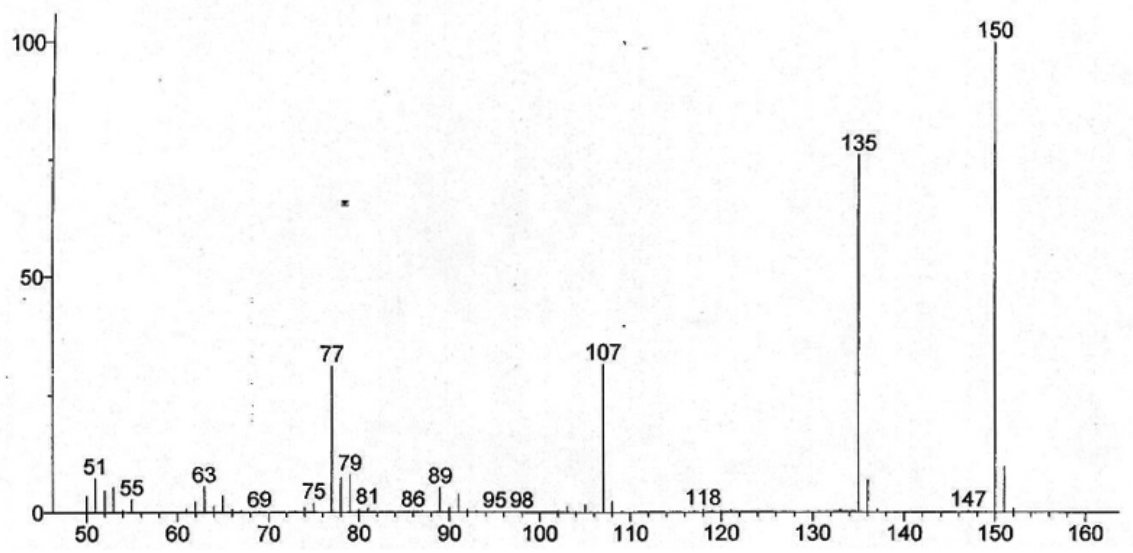

Mass Spectrum of Product 